\title{
Assessing climate impact on reinforced concrete durability with a multi-physics model
}

\author{
Michel, Alexander; Flint, Madeleine M.
}

Publication date:

2017

Document Version

Peer reviewed version

Link back to DTU Orbit

Citation (APA):

Michel, A., \& Flint, M. M. (2017). Assessing climate impact on reinforced concrete durability with a multi-physics model. Paper presented at 39th IABSE Symposium, Vancouver, Canada.

\section{General rights}

Copyright and moral rights for the publications made accessible in the public portal are retained by the authors and/or other copyright owners and it is a condition of accessing publications that users recognise and abide by the legal requirements associated with these rights.

- Users may download and print one copy of any publication from the public portal for the purpose of private study or research.

- You may not further distribute the material or use it for any profit-making activity or commercial gain

- You may freely distribute the URL identifying the publication in the public portal

If you believe that this document breaches copyright please contact us providing details, and we will remove access to the work immediately and investigate your claim. 


\title{
Assessing climate impact on reinforced concrete durability with a multi-physics model
}

\author{
Madeleine M. Flint \\ Virginia Tech, Blacksburg, VA, USA
}

\author{
Alexander Michel \\ Technical University of Denmark, Kongens Lyngby, Denmark
}

Contact: madeleine.flint@vt.edu

\begin{abstract}
A framework for performance-based durability engineering can incorporate climate impacts in its assessment of the lifetime sustainability of built infrastructure. Most performance-based durability and climate impact assessments have used simplified deterioration models, which are insensitive to shorter-term fluctuations in boundary conditions and therefore may underestimate climate change impacts. A highly sensitive fully-coupled, validated, multi-physics model for heat, moisture and ion transport and corrosion was used to assess a reinforced concrete structure located in coastal Norfolk, Virginia. Deterioration was predicted using tidal exposure conditions obtained from statistically downscaled global climate model output under two emissions scenarios. Deterioration, repair, and decision metrics under the emissions scenarios were compared using the performance-based framework to assess the influence of climate change.
\end{abstract}

Keywords: durability; performance-based; reinforced concrete; corrosion; climate change; hygrothermal; chlorides.

\section{Introduction}

Climate change has long been expected to increase the rate of damage accumulation of built infrastructure, both through more severe deterioration and through increased damage during extreme events such as hurricanes. As a globally favoured building material, any change in the rate of deterioration in reinforced concrete (RC) structures would be expected to result in significant impacts. RC is particularly susceptible to chloride-induced corrosion, which can lead to both serviceability and safety issues. Chlorideinduced corrosion is a highly complex, coupled stochastic process; combining the stochastic nature of corrosion with the high uncertainty associated with both global and local climate change makes quantifying potential climate impacts challenging. It is a further challenge to link changing deterioration rates to more tangible decision-making information such as costs, as would be needed to support adaptation.

A number of researchers have developed probabilistic approaches for assessing climate impacts on durability of structures exposed to chlorides. Previous studies have indicated a potential decrease in time to failure by $<1 \%$ to $>30 \%$ [1-3]. However, these studies have generally used deterioration models that are not particularly sensitive to changes in boundary 
conditions, e.g., apparent Fickian diffusion models for chloride ingress [2,3], or one-way coupled models for heat and mass transport [1]. Deterioration models that are sensitive to boundary conditions tend to require surface boundary conditions at high temporal resolution [4], making them difficult to implement in the context of a non-stationary climate. Given that archives of projections from global climate models (GCMs) generally only contain limited meteorological variables at course spatial and temporal resolution, significant effort is required to bridge the gap between available data and model requirements.

One approach that has previously been used to assess potential climate impacts, termed performance-based durability engineering (PBDE), comprehensively considers uncertainty in four analysis stages of climatic exposure, deterioration, repair, and decision information, as shown in Fig. 1 [3]. Uncertainty is characterized at each analysis stage through use of generic "pinch-point" variables $\left(E C, D M, t_{R A}\right.$, and $D I$ as shown in Fig. 1) that are selected as appropriate to the site, structure, and deterioration mechanism studied. Probabilistic distributions are obtained for all pinch-point variables, either from expert judgment (common for $E C$ and $D I$ ) or from simulation (common for $D M$ and $t_{R A}$ ). In the case of the latter variables, conditional distributions are used $\left(f_{D M \mid E C}, f_{t_{R A} \mid E C}\right.$ when described continuously or $p_{t_{R A} \mid E C}$ if discrete, and $f_{D I \mid t_{R A}}$ ).

\begin{tabular}{|c|c|c|c|}
\hline $\begin{array}{c}\text { Exposure } \\
\text { Analysis } \\
\text { Exposure } \\
\text { Conditions } \\
(E C) \\
\begin{array}{c}\text { e.g. sea } \\
\text { level rise }\end{array}\end{array} \overbrace{\begin{array}{c}\text { Deterioration } \\
\text { Analysis } \\
\text { Damage } \\
\text { Measures } \\
(D M) \\
\text { e.g. } \\
\text { corrosion }\end{array}} \begin{array}{c}\text { Repair } \\
\text { Analysis } \\
\text { Repair } \\
\text { Actions } \\
\left(t_{R A}\right) \\
\text { e.g. cathodic } \\
\text { protection }\end{array}$ \\
\hline
\end{tabular}

Figure 1. Performance-based durability engineering analyses and pinch-points

Using the Total Probability Theorem, the conditional distributions can then be convolved to obtain lifetime distributions of the $\mathrm{DI}$, as shown in Eq. 1. Because discrete probability mass functions are usually used to describe the repair action timing, this convolution equation is partially replaced by a summation.

$$
\begin{aligned}
& f_{D I}=\iint f_{D I \mid t_{R A}} f_{t_{R A} \mid E C} f_{E C} \mathrm{~d} t_{r a} \mathrm{~d} e c \\
& =\sum_{j=1}^{n_{t_{R A}}} \int f_{D I \mid t_{R A}} p_{t_{R A} \mid E C} f_{E C} \mathrm{~d} e c
\end{aligned}
$$

Uncertainty in each pinch-point variable can be "deaggregated" by skipping one of the integrations, e.g., a conditional distribution for cost given sea level rise $\left(f_{D I \mid E C}\right)$ could be obtained. Such conditional distributions are particularly useful for sensitivity assessment.

In this paper the PBDE framework is implemented using a multi-physics model for chloride-induced corrosion in RC to investigate the impact of climate change on deterioration and cost. The case study site in the mid-Atlantic region of the United States experiences tidal exposure, where change in deterioration patterns is expected due to both change in atmospheric conditions (i.e. warming) and sea level rise (SLR). Section 2 describes the case study site, structure, models, and assumptions. Section 3 presents conditional and final results as well as results deaggregated based by exposure severity. Section 4 discusses limitations, describes future work, and provides conclusions.

\section{Methods}

\subsection{Site and structure}

The site is located in Norfolk, Virginia, a coastal region subjected to locally high levels of sea level rise [5]. This region has historically experienced high levels of corrosion in RC bridges [6].

The hypothetical RC structural element analyzed was assumed to experience sheltered tidal exposure, such that at regular intervals the exposure changed from ambient air temperature and humidity (but no sunlight or wind) to submerged conditions. Such exposure would be consistent with the underside (soffit) of a pier or portions of a bridge substructure. The structure was assumed to be constructed of ordinary Portland cement concrete with black steel reinforcement. The water-to-cement ratio was assumed to be 0.4 and representative heat and 
mass transport and storage parameters were selected for the hypothetical material. The structure was assumed to include three reinforcement bars with a diameter of $16 \mathrm{~mm}$ and a distance between bars of $10 \mathrm{~mm}$. The cover depth was $70 \mathrm{~mm}$ and the total depth of the structural element was assumed to be $200 \mathrm{~mm}$. The elevation of the element was assumed to be $0.66 \mathrm{~m}$ above the mean lower low water mark (MLLW) from year 2000.

\subsection{Climate and exposure}

Exposure analysis requires characterizing the Exposure Condition $(E C)$ and all other required boundary conditions. Two representative concentration pathways (RCP 2.6 and RCP 8.5) of change in climate forcing by the end of the $21^{\text {st }}$ century [7] were selected and evaluated separately.

\subsubsection{Exposure Condition: sea level rise}

The degree of local SLR at Sewell's Point in Norfolk was selected as the $E C$, and was discretized at the $17^{\text {th }}, 50^{\text {th }}$, and $83^{\text {rd }}$ percentiles for the two RCPs [5]. A series of quadratic fits was performed for each SLR probability/RCP combination based on the values provided in [5] for years 2030, 2050, and $2100\left(R^{2}\right.$ all $\left.>0.995\right)$. The SLR fits as well as the underlying tidal variations (from observations, see Section 3.2.3) are shown in Fig. 2.

\subsubsection{Climate model data}

In order to capture climate uncertainty, 5 simulations from two global climate models (GCMs) were used: canESM2 and CSIRO-Mk3.6.0. A set of downscaled $\left(1 / 8^{\text {th }}\right.$ degree $)$ and biascorrected daily maximum and minimum air temperature from 2000-2099 was obtained from [8] and used. The two GCMs were assumed to produce equally appropriate projections. Thus for each PBDE assessment a total of 30 sets of exposure conditions were obtained ( 1 RCP, 3 values of SLR, 2 GCMs, 5 runs). It is noted that the sources of the local SLR projections were obtained from an ensemble of a larger number of GCMs, and are not directly consistent with the GCMs and individual simulations used. However, the value of using SLR projections that take into account local was deemed to outweigh the inconsistency.

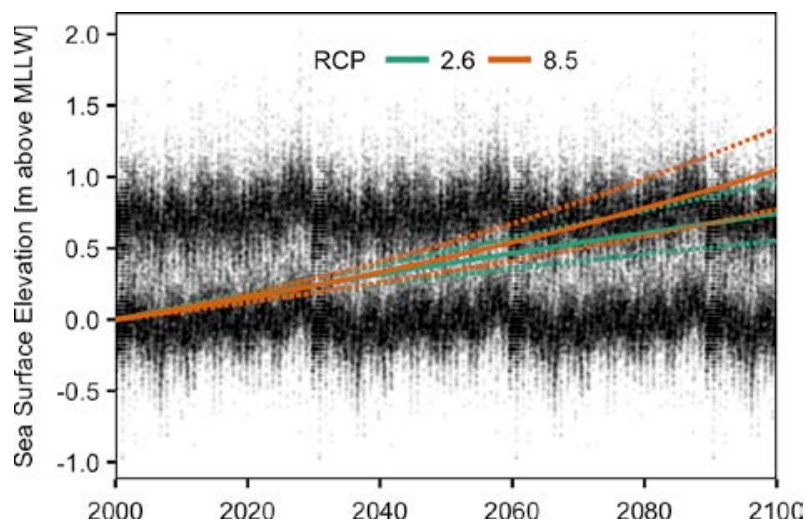

Figure 2. Observed Sewell's Point tide data (points: 1970-1999 daily max/min, repeated) and quadratic fit to median (solid line) and $17^{\text {th }} / 83^{\text {rd }}$ percentile (dotted line) local SLR projections

\subsubsection{Atmospheric boundary conditions}

Meteorological data from 1970-1999 was obtained from NOAA for a local weather station (Norfolk International Airport). The values and times of the daily temperature $(T)$ and relative humidity (RH) extremes were identified and collected by date (e.g., "January 1"). Because appropriate parametric distributions could not be identified, these empirical distributions were sampled to obtain the timing of the extremes ( $T$ and $\mathrm{RH}$ ) and values (RH only). This approach maintains the seasonality of the data, and was deemed acceptable given the low sub-annual autocorrelation and cross-correlation of all variables $(|\rho|<0.5$, usually $<0.25)$. The only variables that were not independently sampled were the RH values, which were correlated $(\rho=0.58)$ and therefore sampled jointly. Once the times of the daily extremes had been assigned for each day, hourly $\mathrm{T}$ and $\mathrm{RH}$ values were obtained through linear interpolation.

The surface chloride concentration was held constant at $120 \mathrm{~mol} / \mathrm{m}^{3}$. This value is within the range used in other climate impact studies, e.g., $[2,4,9]$. The oxygen concentration was taken as $8.69 \mathrm{~mol} / \mathrm{m}^{3}$.

\subsubsection{Submerged boundary conditions}

In order to capture the tidal exposure it was necessary to determine times when the structure 
would be submerged and the conditions during submersion. A set of 1970-1999 hourly baseline tide data was obtained from NOAA for Sewell's Point. While some local SLR during the baseline period in the mid-Atlantic region was reported in [5], the Mann-Kendall trend test revealed a small decreasing trend in the tidal record. The data was therefore not de-trended. Linear interpolation of the tide record was used to identify the submersion periods; hours where more than 30 minutes were submerged were set to submerged boundary conditions.

During submersion the $\mathrm{RH}$ value was set to 100 . For consistency, the $T$ value should be set to the sea surface temperature (SST), which generally varies by $4-6^{\circ} \mathrm{C}$ from the air temperature and may lag by days or months [10]. Mid-Atlantic SST data from the World Ocean Database was obtained, but was insufficient to relate air and sea surface temperature in the region. Due to the lack of SST data the air temperature values were also used during submersion, which may introduce some bias in the deterioration predictions.

During submersion the oxygen concentration was set to $0.27 \mathrm{~mol} / \mathrm{m}^{3}$ and the chloride concentration was again held constant at $120 \mathrm{~mol} / \mathrm{m}^{3}$ (noting that the concentration in seawater is approximately $550 \mathrm{~mol} / \mathrm{m}^{3}$ ).

\subsection{Deterioration}

\subsubsection{Heat and mass transport model}

The 1D fully-coupled heat and transport model was also used in [4], and solves partial differential equations for heat transport (nonlinear heat equation), liquid and vapour moisture transport (Richard's equation), and the transport of various chemical species (Nernst-Planck equation). State variables were: logarithm of the capillary pressure; temperature; and concentration of the chemical species $\left(\mathrm{O}_{2}, \mathrm{Cl}^{-}, \mathrm{Na}^{+}, \mathrm{OH}^{-}, \mathrm{K}^{+}, \mathrm{Ca}^{2+}, \mathrm{SO}^{2-}{ }_{4}\right)$.

Constitutive equations are also described in [4], and include various transport coefficients for fullycoupled heat and moisture transport in porous media, the van Genuchten function for moisture storage, and a Langmuir binding isotherm for the chloride diffusion coefficient. Additional coupling terms based on empirical data (and described in
[4]) couple the moisture storage behaviour to both the chloride concentration and the temperature. Heat and ionic transport parameters were the same as described in [4]; parameter values and initial conditions that differ from those used in [4] are presented in Table 1.

Table 1: Transport parameters and initial conditions

\begin{tabular}{|c|c|c|}
\hline & Parameter [units] & Value \\
\hline \multirow{2}{*}{$\begin{array}{l}\text { Moisture } \\
\text { transport }\end{array}$} & Saturated conductivity $\mathrm{K}_{\mathrm{I}, \text { sat }}[\mathrm{s}]$ & $1 \mathrm{E}-9$ \\
\hline & $\begin{array}{l}\text { Non-physical model parameter } \\
\qquad n_{\mathrm{SP}}[-]\end{array}$ & 2 \\
\hline \multirow{2}{*}{$\begin{array}{l}\text { Initial } \\
\text { Conditions }\end{array}$} & $\begin{array}{l}\text { Initial ion concentration } \mathrm{c}_{\mathrm{i}, 0} \\
{\left[\mathrm{~mol} / \mathrm{m}^{3}\right]}\end{array}$ & $\begin{array}{l}\text { Varies, } \\
\text { see [11] }\end{array}$ \\
\hline & $\begin{array}{l}\text { Initial oxygen concentration } \\
\qquad \mathrm{C}_{\mathrm{O} 2,0}\left[\mathrm{~mol} / \mathrm{m}^{3}\right]\end{array}$ & 8.69 \\
\hline
\end{tabular}

\subsubsection{Corrosion model}

Laplace's equation is used to describe the potential distribution in concrete assuming electrical charge conservation and isotropic conductivity, while Ohm's law is used to determine the corrosion current density $\left(i_{\text {corr }}\right)$ from the potential distribution and resistivity of the electrolyte. Kinetics of electrochemical processes are described by anodic and cathodic polarization curves, which comprise activation and concentration polarization. These electrochemical processes are coupled with transport to account for the impact of temperature, moisture, and oxygen on corrosion. To link initiation (i.e., the formation of anodic regions) with propagation of reinforcement corrosion, a conditional statement is defined for the critical chloride threshold along the reinforcement surface. More detailed information on the modelling of reinforcement corrosion and the coupling with transport of heat and matter can be found in $[12,13]$.

Using Faraday's law (see [4] for details), the corrosion current density was linked to reinforcement loss and tied to delamination using a critical value of bar radius loss (see Table 2).

\subsubsection{Parameter uncertainty}

Uncertainty in the deterioration analysis was attributed to one parameter: the critical chloride 
concentration to initiate corrosion $\left(C_{C l}^{c r}\right)$, which was assumed normally distributed. Distribution information is provided in Table 1. A 3-sample Latin hypercube was used to select pairs of values for two bars. The use of Latin hypercube sampling was previously found to produce accurate results in PBDE with reduced computational expense as opposed to Monte Carlo simulation [3].

Table 2. Deterioration and Cost Parameters

\begin{tabular}{ccc}
\hline Parameter [units] & Mean & COV \\
\hline Rebar $1 C_{C l}^{c r}\left[\mathrm{~mol} / \mathrm{m}^{3}\right]$ & 80 & 0.2 \\
\hline Rebar $2 C_{C l}^{c r}\left[\mathrm{~mol} / \mathrm{m}^{3}\right]$ & 60 & 0.1 \\
\hline Rebar $\Delta r^{c r}[\mathrm{~mm}]$ & 0.08 & 0 \\
\hline $\mathrm{CP}$ install $\left[\mathrm{USD} / \mathrm{m}^{2}\right]$ & 120 & 0.2 \\
\hline $\mathrm{CP}$ maintain $\left[\mathrm{USD} / \mathrm{m}^{2} / \mathrm{yr}\right]$ & 2 & 0.2 \\
\hline Replace $\left[\mathrm{USD} / \mathrm{m}^{2}\right]$ & 190 & 0.25 \\
\hline
\end{tabular}

\subsection{Repair and rehabilitation}

A simple repair decision tree was developed and is shown in Fig. 3. Based on a quadrennial routine visual inspection on July 1 , the presence of cracking or delamination would lead to one of three actions: replacing the structural element if more than 35 years of additional service are required; installing cathodic protection $(\mathrm{CP})$ if less than 35 years of service is required; and doing nothing if less than 10 years of service is required. This repair tree is based on estimates of a 35-year functional service life for cathodic protection systems in Virginia [6]. The replacement and/or installation of $C P$ were assumed to take place 2 years after the failed inspection. Both the replacement and $\mathrm{CP}$ installation were assumed to be perfect in preventing any future deterioration.

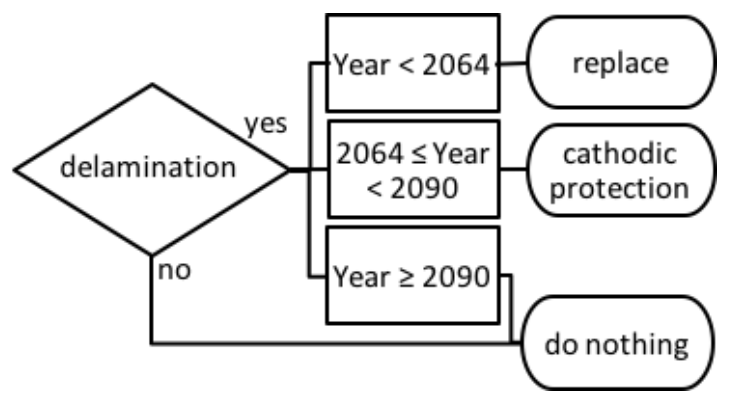

Figure 3. Hypothetical repair decision tree
The repair tree yielded 23 combinations of selected $R A$ and timing. The combinations comprise 15 timings of replacement, 7 timings of CP application, and the "do nothing" case.

\subsection{Decision information}

Cost data per square meter of replacement or repair area was obtained based on local data for RC bridges [6]. The parameters for the normal distributions of CP installation and ongoing costs, as well as replacement, are presented in Table 1. It is noted that year 2064 is the "break-even" point for the expected cost of installing and maintain CP for 35 years - as opposed to replacing the structure-which informed the development of the repair decision tree.

A net-present value calculation with discount rate of $2 \%$ was used to standardize costs to year-2000 USD. Because both the initial and ongoing costs were assumed to be normally distributed it was possible to directly obtain the parameters for the (normally distributed) discounted cost.

\section{Results}

\subsection{Conditional results}

Selected simulations of the chloride concentration at reinforcement depth are shown in Fig. 4, for the RCP 8.5 scenario and with the EC equal to $83^{\text {rd }}$ percentile for SLR. The plot of each simulation was truncated as a repair action was undertaken. In all simulations replacement timings were very early, with the majority happening before 2026 and the latest happening in 2054. Due to the early replacements no simulations selected cathodic protection as the $R A$.

Considering the results shown in Fig. 4-as well as other results not shown-there was not a considerable difference in deterioration simulations produced using the two GCMs, and the selection of the critical chloride content parameter was more influential on deterioration predictions than record-to-record variability. The simulations showed consistent behaviour in that high corrosion current densities (max: 1.8$2.5 \mu \mathrm{A} / \mathrm{cm}^{2}$ ) would be observed shortly after initiation in one rebar, which would then be 
reduced as active corrosion initiated on a second rebar (median post-initiation: $0.01-0.295 \mu \mathrm{A} / \mathrm{cm}^{2}$ ).

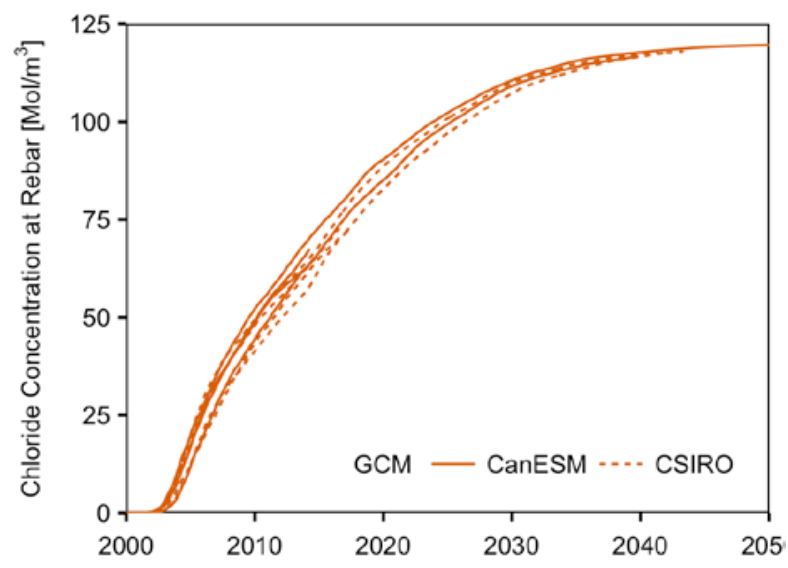

Figure 4. Individual simulations of chloride concentration at reinforcement depth for RCP 8.5, given $83^{\text {rd }}$ quantile of SLR; 2 sets of parameters for 2 records are shown for each GCM

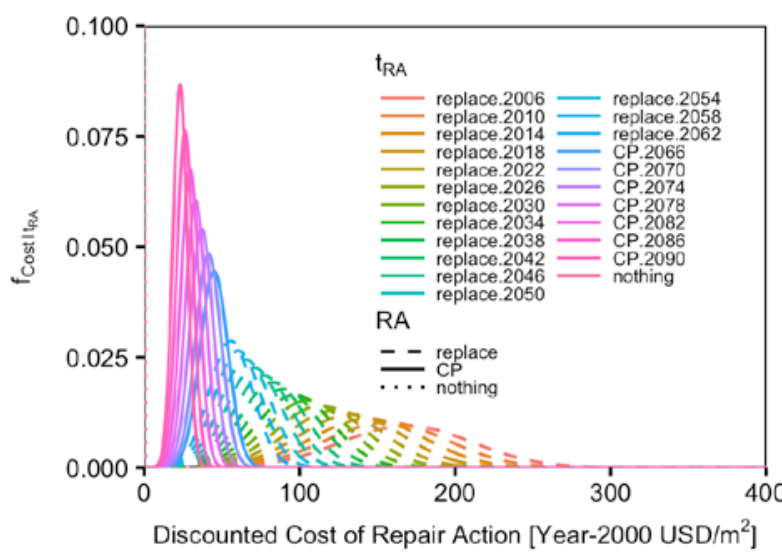

Figure 5. Conditional probability densities of cost of repair action timings

Fig. 5 shows the conditional distributions for cost given each of the 23 possible $R A$ timings. The effect of the discounting was significant, as the earlier replacement actions were associated with much higher means and variances, whereas the later CP actions had low means and variances. Given the smooth transitions between the distributions of the individual $R A$ timings, it would be expected that the convolved cost distribution would be reasonably smooth.

\subsection{Convolved results}

The probability mass functions for the repair action timings under the two emissions scenarios are shown in Fig. 6 . The results under the two
RCPs were very similar; RCP 2.6 had a slight tendency towards earlier repairs. The lack of a consistent trend was attributed to the nonlinearity of the deterioration predictions, i.e., it would not be expected that a set of increments in the exposure would necessarily lead to uniform increments in deterioration and thus repair.

Fig. 7 presents the final distribution for lifetime discounted cost, which was obtained by convolving the data shown in Figs. 5 and 6 . Based on the prior discussion of Figs. 5 and 6, it is not surprising that the two cost distributions are (a) relatively smooth, and (b) very similar.

The expected lifetime costs are provided in Table 3: there was essentially no difference in expected costs under the two emissions scenarios. Because of discounting the expected cost is significantly less than the mean cost for replacement.

Table 3. Expected Costs in Year-2000 USD $/ \mathrm{m}^{2}$

\begin{tabular}{ccccc}
\hline Analysis & Final & $\mid e c_{1}$ & $\mid e c_{2}$ & $\mid e c_{3}$ \\
\hline RCP 2.6 & 118.13 & 120.74 & 116.29 & 117.35 \\
\hline RCP 8.5 & 118.28 & 125.64 & 115.46 & 113.74 \\
\hline
\end{tabular}

\subsection{Climate sensitivity}

The conditional and convolved results show low variation with RCP, which was confirmed with deaggregation. Fig. 8 shows the deaggregated distribution of lifetime discounted cost for the 3 individual values of $E C$. While the shapes of the distributions vary slightly (as they are associated with different sets of $R A$ timing), the central values are similar, as shown in Table 3 . There was no clear trend related to the degree of SLR.

\section{Summary and conclusions}

A multi-physics deterioration model was used in a preliminary performance-based assessment to characterize the lifetime cost of repairing a reinforced concrete structure subjected to tidal exposure. The combination of the concrete and exposure studied led to early ( $<20$ year) initiation of corrosion, and consequently low sensitivity to global warming and sea level rise. This low sensitivity was evident under two emissions 
scenarios that characterize the lowest and highest levels of climate forcings modelled in CMIP5.
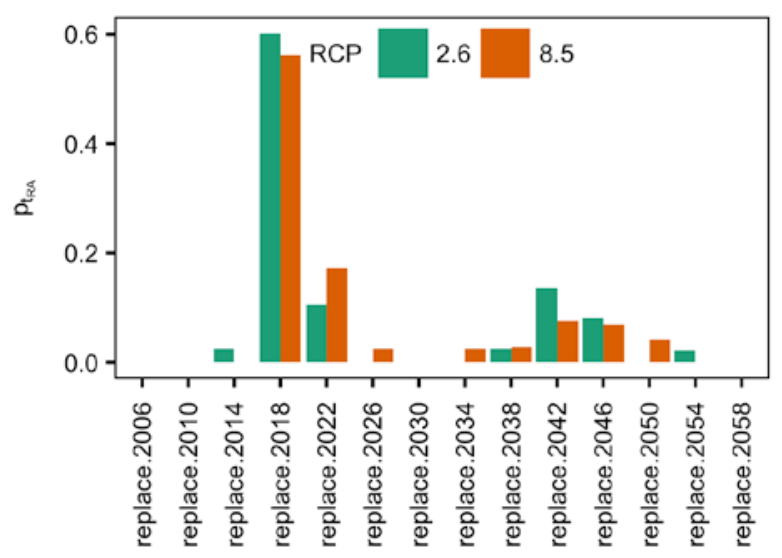

Figure 6. Probability of repair action timings

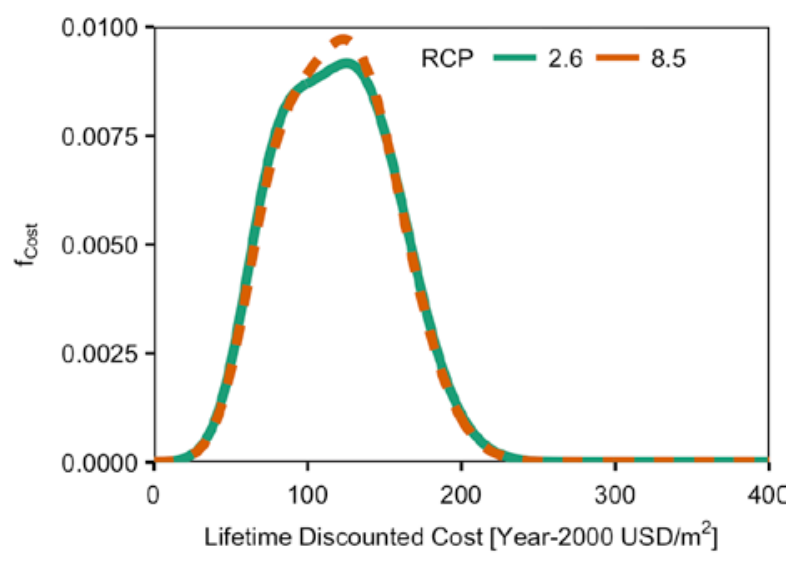

Figure 7. Probability density of discounted lifetime cost to replace the structural element

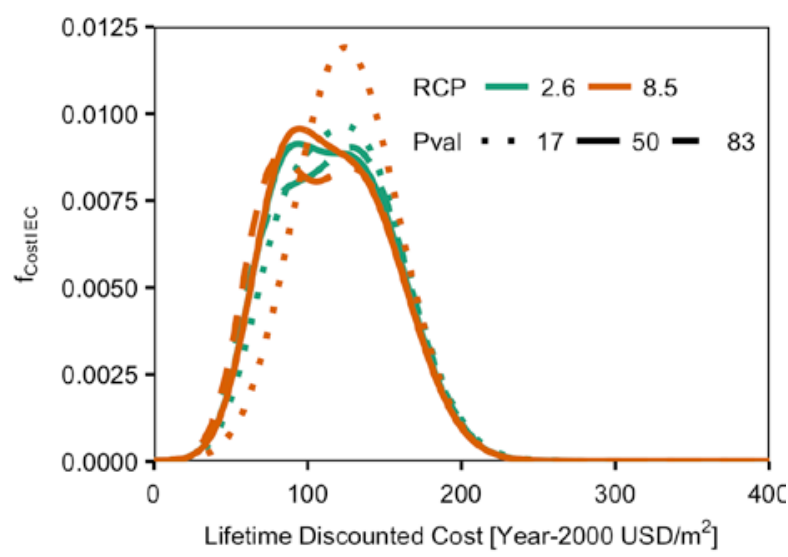

Figure 8. Deaggregated distributions of discounted lifetime cost for three quantiles of SLR

Due to its preliminary nature, a number of simplifications were made in the PBDE assessment. In particular, simplifications included the use of only: 3 values of exposure condition (sea level rise); 2 global climate models; and 3 Latin hypercube samples of a single stochastic deterioration parameter (critical chloride content). Future work would ideally: refine the discretization of the exposure condition; consider additional GCMs; generate additional exposure records from each individual GCM projection; consider additional deterioration parameters; implement a more realistic repair decision tree; and include additional decision information, e.g., downtime. It would also be of interest to isolate the effects of tidal extremes (from tropical storms) on deterioration patterns.

Perhaps more importantly, the development of the exposure records required several limitingand possibly biasing-assumptions. In order to accurately characterize future deterioration, the development of exposure records should address the following issues (in order of criticality):

- Relative humidity projections should be obtained, downscaled and bias-corrected

- Sea surface, not air, temperature should be applied during submersion; similarly the oxygen and chloride content of seawater should be selected based on local observations

- The random assignment of the times of daily temperature and humidity extremes, as well as the use of linear interpolation, should be evaluated against the hourly baseline meteorological observations

- A longer baseline period should be considered given that 100 years of data must be generated from the observations

- The probabilities of sea level rise should be made consistent with each GCM

Because (a) the consequences of assumptions made were not fully investigated, and (b) the sensitivity of the multi-physics deterioration to tidal exposure has not been fully characterized, deterioration results from this study cannot be generalized with regard to the effect of climate change. Despite these limitations, this study demonstrates the potential value of integrating multi-physics deterioration models into the framework for PBDE to assess climate impacts. 


\section{References}

[1] Bastidas-Arteaga E., Chateauneuf a., Sánchez-Silva M., Bressolette P., and Schoefs F. Influence of weather and global warming in chloride ingress into concrete: A stochastic approach. Structural Safety. 2010;32(4):238-49.

[2] Bastidas-Arteaga E., Schoefs F., Stewart M.G., and Wang $X$. Influence of global warming on durability of corroding RC structures: A probabilistic approach. Engineering Structures. 2013;51:259-66.

[3] Flint M.M., Baker J.W., and Billington S.L. A modular framework for performancebased durability engineering: From exposure to impacts. Structural Safety. 2014;50:78-93.

[4] Flint M., Michel A., Billington S.L., and Geiker M.R. Influence of temporal resolution and processing of exposure data on modeling of chloride ingress and reinforcement corrosion in concrete. Materials and Structures. 2014;47(4):72948.

[5] Kopp R.E., Horton R.M., Little C.M., Mitrovica J.X., Oppenheimer M., Rasmussen D.J., et al. Probabilistic 21st and 22nd century sea-level projections at a global network of tide-gauge sites. Earth's Future. 2014;2(8):383-406.

[6] Sharp S.R., and Brown M.C. Survey of Cathodic Protection Systems on Virginia Bridges. Vol. FHWA/VTRC, Physical Therapy. Charlottesville, VA; 2007.

[7] van Vuuren D.P., Edmonds J., Kainuma M., Riahi K., Thomson A., Hibbard K., et al. The representative concentration pathways: an overview. Climatic Change. 2011;109(12):5-31.

[8] Bureau of Reclamation. Downscaled CMIP3 and CMIP5 Climate Projections: Release of Downscaled CMIP5 Climate Projections, Comparison with Preceding Information, and Summary of User Needs. Washington DC: US Department of the Interior; 2013.
[9] Stewart M.G., Wang X., and Nguyen M.N. Climate change impact and risks of concrete infrastructure deterioration. Engineering Structures. 2011;33(4):132637.

[10] Palmer T.N., and Zhaobo S. A modelling and observational study of the relationship between sea surface temperature in the North-West atlantic and the atmospheric general circulation. Quarterly Journal of the Royal Meteorological Society. 1985;111(470):947-75.

[11] Johannesson B., Yamada K., Nilsson L.-O., and Hosokawa Y. Multi-species ionic diffusion in concrete with account to interaction between ions in the pore solution and the cement hydrates. Materials and Structures. 2007;40(7):65165.

[12] Michel A., Otieno M., Stang H., and Geiker M.R. Propagation of steel corrosion in concrete: Experimental and numerical investigations. Cement and Concrete Composites. 2016;70:171-82.

[13] Michel A., Geiker M.R., Stang H., and Lepech M. Multi-Physics and Multi-Scale Deterioration Modelling of Reinforced Concrete Part I: Coupling Transport and Corrosion At the Material Scale. In: 2015 Symposium of the Federation Internationale du Beton (fib). Copehnagen, Denmark: fib; 2015. 